\title{
НАУЧНО-МЕТОДИЧЕСКОЕ ОБЕСПЕЧЕНИЕ ДЕЯТЕЛЬНОСТИ ПЕДАГОГА-ЭКСПЕРИМЕНТАТОРА ПО ДУХОВНО-НРАВСТВЕННОМУ ВОСПИТАНИЮ ДОШКОЛЬНИКОВ СРЕДСТВАМИ КРАЕВЕДЕНИЯ: ОТ СОЗЕРЦАНИЯ ПРОБЛЕМЫ К ПРОЕКТИРОВАНИЮ И РЕЗУЛЬТАТАМ
}

\section{SCIENTIFIC AND METHODOLOGICAL SUPPORT OF THE ACTIVITY OF AN EXPERIMENTAL TEACHER ON THE SPIRITUAL AND MORAL EDUCATION OF PRESCHOOLERS BY MEANS OF LOCAL HISTORY: FROM CONTEMPLATION OF THE PROBLEM TO DESIGN AND RESULTS}

L. Savinova

K. Yanakova

Summary: The relevance of the materials presented in the article is due to the need to use modern approaches to the organization of methodological support for the activities of experimental teachers on the spiritual and moral education of preschoolers by means of local history in an innovative educational institution. The results of the study are presented, reflecting the ideas of teachers about the organization of targeted methodological support for their activities. The components of methodological support and their content content within the framework of the DOW are disclosed. The use of the context of local history in the spiritual and moral education of children expands the opportunities and prospects of innovative activity of teachers.

Keywords: methodological support for the activities of experimental teachers, components of methodological support, content and forms of methodological support.

\author{
Савинова Людмила Фёдоровна \\ д.n.н., nрофрессор, ФГБОУ ВО «Карачаево-Черкесский \\ государственный университет им У.Д. Алиева», \\ 2. Карачаевск \\ Янакова Кристина Геннадьевна \\ Аспирант, ФГБОУ ВО «Карачаево-Черкесский \\ государственный университет им. У.Д. Алиева», \\ г. Карачаевск \\ porshe0911@mail.ru
}

Аннотация: Актуальность материалов, изложенных в статье, обусловлена потребностью использования современных подходов к организации методического обеспечения деятельности педагогов-экспериментаторов по духовно-нравственному воспитанию дошкольников средствами краеведения в условиях инновационного образовательного учреждения. Представлены результаты исследования, отражающие представления педагогов об организации адресного методического обеспечения их деятельности. Раскрыты компоненты методического обеспечения и их содержательное наполнение в рамках ДОУ. Использование контекста краеведения в духовно-нравственном воспитании детей расширяет возможности и перспективы инновационной деятельности педагогов.

Ключевые слова: методическое обеспечение деятельности педагогов-экспериментаторов, компоненты методического обеспечения, содержание и формы методического обеспечения.
Л огику рассмотрения обозначенной проблемы целесообразно обозначить так: «от созерцания проблемы к проектированию её решения и результатам».

Деятельность педагогов-экспериментаторов имеет свои особенности, обусловленные тем, что от них требуется образовательная деятельность с качественно иным содержанием адекватным проблематике эксперимента. Традиционный функционал деятельности педагога: обучающий, развивающий и воспитательный пополняется новой функцией - исследовательской. На эту особенность обращает внимание Т.М. Ковалёва, подчёркивая, что «образовательный процесс, разворачиваемый в экспериментальном образовательном процессе, требует наличия новой педагогической позиции - позиции педагога-исследователя». [3, с.41]. Таким образом, происходит смена ориентиров на оптимальное использование возможностей личности, что обусловливает активное участие педагога в экспериментальной деятельности.

Вместе с тем практика показывает, что большинство педагогов ДОУ не готовы к экспериментальной деятельности по проблеме исследования. Наиболее уязвимым местом является научно-методическое обеспечение деятельности педагогов-экспериментаторов. Опрос, про- 
ведённый нами перед началом эксперимента (2018 г.), с педагогами дошкольных образовательных учреждений г. Ставрополя, Ессентуки и Предгорного района Ставропольского края показал, что 72\% респондентов из 100 опрошенных не владеют технологией разработки нового содержания, формами и методами работы с детьми по духовно-нравственному воспитанию детей с использованием потенциала краеведения. Респонденты указали и основную причину такого положения: исследуемое направление воспитания является новым направлением в деятельности ДОУ, продуцирует деятельность педагогов на поиск научно-методических нововведений в педагогическую систему. Из-за недостатка знаний и времени педагоги не знают как работать в экспериментальном режиме.

Приведённые выше факты способствовали тому, что в течение четырёх лет, начиная с 2018 года, в ДОУ №17, №18, №20 станицы Суворовской Предгорного округа Ставропольского края реализуется проект по теме: «Методическое обеспечение деятельности педагога по духовно-нравственному воспитанию детей старшего дошкольного возраста средствами краеведения».

Целью проекта стало создание условий для осуществления компетентной деятельности педагогов по духовно-нравственному воспитанию старших дошкольников средствами краеведения. Профессионально компетентным можно считать такого педагога, который на достаточно высоком уровне осуществляет педагогическую деятельность в исследуемом направлении воспитания, в совершенстве владеет способами использования в этой работе средств краеведения. В соответствии с целью в проекте были поставлены следующие задачи: усиление адресной помощи в информационно-методическом обеспечении; оперативное реагирование на запросы педагогов; поддержка инициатив педагогов и индивидуального стиля деятельности; ориентация на создание авторской педагогической системы.

Технология конструирования системы методического обеспечения деятельности педагогов-экспериментаторов проектируется на основе методологических подходов В.И. Загвязинского, А.М. Новикова, А.М. Саранова, и представляет собой совокупность трёх стадий: проектировочной, экспериментальной и рефлексивно-оценивающей. $[2,4,5]$.

Работа на проектировочной стадии начинается с разработки модели нового научно-методического обеспечения деятельности педагогов-экспериментаторов в контексте целей и задач проекта.

По версии нашего исследования, методическое обеспечение представляет собой важное направление методической работы, мотивирующее развитие креативных способностей педагогов, познавательно-ценностных интересов, а также профессиональных и личностных факторов роста и профессионального мастерства.

Методическое обеспечение выступает как конструкт диагностической, организационной, образовательной, инновационной и прогностической деятельности педагогов дошкольного образовательного учреждения.

В подготовленной нами статье «Модель методического обеспечения деятельности педагогов-экспериментаторов по духовно-нравственному воспитанию дошкольников средствами краеведения» подробно описаны три модуля модели: целевой, содержательно-процессуальный и оценочно-результативный, а также условия её реализации. [6]. В данной публикации сделан акцент на раскрытии содержания и форм всех компонентов методического обеспечения деятельности педагогов-экспериментаторов.

В модели определены четыре компонента методического обеспечения деятельности педагогов-экспериментаторов: мотивационное, учебно-методическое, информационно-аналитическое, научно-практическое.

На втором этапе конструирования системы методического обеспечения деятельности педагогов-экспериментаторов - экспериментальном - все компоненты методической системы были наполнены специфическим содержанием в контексте проблематики проекта.

Координирующую роль в повышении мотивации педагогов к участию в проекте сыграл педагогический совет, который стимулировал участие педагогов не только в педсоветах, но и в проектировании инновационной методической системы работы воспитателя. Так, по решению одного из заседаний педсовета были созданы творческие группы педагогов по таким направлениям: «Обновление программы «Университета родителей» в контексте задач проекта», «Игра на занятиях, как способ духовно-нравственного воспитания детей на занятиях литературного творчества», «Коллекция педагогического инструментария по краеведению», «Опыт: пути и способы распространения». Перечисленные направления заседаний творческих групп являются не только актуальными, но и помогают решить многие проблемы.

Например, конечным продуктом деятельности творческой группы «Опыт: пути и способы распространения» стала разработанная в ходе обсуждения карта анализа собственного опыта. В карту включены следующие позиции: направления работы, отражающие сущность собственного педагогического опыта; направления работы, отражающие изменение содержания образования (разработка экспериментального цикла занятий по направлению «Я и природа», «Я и Отечество» и т.д.); направления 
работы, отражающие совершенствование организации педагогического процесса (диагностика, прогнозирование, конструирование педагогического процесса).

Ценно то, что творческая группа определила не только направления исследовательского поиска, но и схему описания педагогического опыта как собственного, так и коллег. В схему входят следующие характеристики: педагогические идеи, основные теоретико-методологические подходы, положенные в основу инновации; характеристики педагогических систем (методической, дидактической, воспитательной, организационно-педагогической); принципы отбора содержания образования, выбора технологий и методов решения исследовательских задач. По нашему убеждению, карта анализа собственного опыта помогла педагогам обобщить опыт в научных публикациях, выступлениях на семинарах, научно-практических конференциях.

Вторым компонентом методического обеспечения деятельности педагогов-экспериментаторов является учебно-методическое обеспечение. Системообразующим элементом содержательного аспекта этого направления является проектирование системы повышения квалификации в условиях дошкольного образовательного учреждения. Вопрос о выборе формы повышения квалификации был обсужден на объединённом заседании творческих групп. Предпочтение было отдано корпоративному семинару - внутриучрежденческой форме повышения квалификации. Такой выбор был аргументирован тем, что обучение на рабочем месте объединяет всех педагогов, работающих над реализацией общей для всех проблемы духовно-нравственного воспитания детей старшего дошкольного возраста средствами краеведения.

Программа корпоративного семинара включает цикл семинаров: «Духовно-нравственное воспитание как целостное педагогическое явление», «Влияние среды на духовно-нравственное воспитание дошкольников», «Наследие веков. Край Ставропольский и его место среди культур других народов Северного Кавказа», «Инновационное развитие дошкольного образовательного учреждения». Позже с учётом заявок педагогов в программу были включены такие темы: «Авторская педагогическая система как результат инновационного поиска», «Проблема разработки содержания и технологий процесса духовно-нравственного воспитания дошкольников средствами краеведения».

Вопросы, поднятые на семинарах, активизировали творческий потенциал педагогов. Например, по инициативе педагогов была создана карта «Вклад выдающихся деятелей страны в развитие культуры Кавказских Минеральных Вод». В этой карте содержатся сведения о деятельности таких выдающихся деятелей-наместни- ках Кавказа: М.С. Воронцове, А.И. Барятинском, враче С.С. Смирнове. Каждый из них внёс вклад в развитие этого региона. Так, М.С. Воронцов заложил парк в Ессентуках, расширил площади парков Пятигорска и Кисловодска. С.А. Смирнов открыл и оборудовал новые источники в Ессентуках и Железноводске и т.д.

Корпоративный семинар был дополнен такой формой повышения квалификации, как педагогическая мастерская. На одном из занятий педагогической мастерской «Проектирование содержания духовно-нравственного воспитания на основе краеведческого компонента» была предложена такая форма работы, как информационно-образовательная карта. Вскоре такая карта «Любознательный малыш» была разработана и внедрена в практику ДОУ. Карта включает пять маршрутов: «Это интересно», «Экскурсии», «Дорога знаний», «Гордость региона», «Совсем рядом», по каждому их которых проводится конкретная работа. Карты содержат фотографии выдающихся личностей, объекты, созданные выдающимися личностями, картины художников, книги поэтов и писателей, фотографии из семейного альбома и т.д.

На заседание педагогической мастерской, на которой разрабатывались методические рекомендации по обоснованию содержания духовно-нравственного воспитания, были приглашены учёные Пятигорского государственного лингвистического университета. С помощью учёных были рассмотрены различные подходы к содержанию духовно-нравственного воспитания. Методологической основой разработки содержания стал подход Е.В. Бондаревской, рассматривающей содержание как «социокультурный опыт, усвоение которого создаёт предпосылки для становления, самореализации личности в контексте культуры». [1, с.482]. В этом контексте содержание духовно-нравственного воспитания представляет комплекс ценностей культуры: жизнь, человек, личность, семья, счастье, честь, ответственность; освоение ценностей человеческой культуры путём ознакомления на экскурсиях, творческих видах деятельности. При этом в рекомендациях подчёркивалось, что содержание духовно-нравственного воспитания не должно регламентироваться. Оно может и должно обогащаться новым содержанием с учётом интересов детей и их возрастных особенностей.

Третье направление методического обеспечения, информационно-аналитическое, в ходе реализации проекта также наполняется адекватным содержанием. Для того, чтобы работа с педагогами была адресной в ведущем учреждении (ДОУ №18) создаётся консалтинговая служба. Концептуальными основами деятельности консалтинговой службы выступают такие направления, как подготовительная работа с педагогами-экспериментаторами, диагностика педагогических затруднений и 
уровня готовности к педагогической экспериментальной деятельности, проектирование способов решения проблем, определение стратегических направлений деятельности ДОУ.

Деятельность консалтинговой службы в ДОУ в информационно-аналитическом направлении ориентирована на выполнение трёх основных функций: информационная, аналитическая, внедренческая. Содержание функций заключается в следующем: 1) сбор информации, анализ и прогнозирование; 2) формирование программы деятельности; 3) осуществление рекламы и трансляции опыта.

Проанализируем более детально, как и в каких направлениях осуществляется консалтинговая помощь. Так, на подготовительном этапе реализации проекта с помощью карты потребностей были выявлены затруднения педагогов-экспериментаторов. Основная потребность педагогов заключалась в недостаточно оперативном информировании их о новых технологиях, методах и методиках осуществления духовно-нравственного воспитания дошкольников средствами краеведения, об адресах ценного опыта экспериментальных доУ. Алгоритм действий консалтинговой службы включает три направления: изучение образовательных потребностей (диагностирование, изучение адресных заявок, собеседование); систематизация и анализ выявленных проблем и запросов педагогов и определение способов и форм оказания помощи педагогам (формирование временных творческих коллективов, адресная работа с педагогами по созданию авторской методической системы, создание мастер-классов). Консалтинговая служба стала инициатором проведения таких мероприятий, как фестиваль «Талант. Мастерство. Авторство», новых форм информирования: экспресс-информация, консилиум.

Научно-практический компонент является четвёртым направлением в методическом обеспечении деятельности педагогов по духовно-нравственному воспитанию детей средствами краеведения. В модели определены формы работы: творческие отчёты, презентация опыта, статьи, научно-методические сборники, выступления на научно-практических конференциях. Перечень исследовательских качеств далеко не полон и он может дополняться.

Работа, проводимая в рамках научно-методического компонента методического обеспечения, оказала плодотворное влияние на деятельность педагогов 70\% из 50 педагогов экспериментальной группы участвуют в разработке методических рекомендаций, проводят открытые занятия, участвуют в научно-практических конференциях. Педагоги стали инициаторами проведения цикла экскурсий «Путешествие по родному краю», игры «Моя станица не похожа на другие сёла», выставок дет- ских поделок и рисунков, театрализованных праздников «Распахни окно в мире прекрасного». В ДОУ создана мини-среда, в которой собраны произведения ставропольских детских писателей и поэтов, картины художников, предметы быта и образцы декоративно-прикладного искусства местных мастеров, работы и предметы, созданные самими детьми, а также медийные информационные ресурсы краеведческих материалов. Вполне вероятно, что в будущем на базе Доу будет создан минимузей.

Таким образом, все компоненты методического обеспечения являются объектами и субъектами взаимодействия. В ходе реализации проекта происходят позитивные изменения в деятельности ДОУ. Об этом свидетельствуют данные диагностического исследования и наши наблюдения. На завершающем этапе реализации проекта 90\% респондентов оценили состояние методического обеспечения как удовлетворительное (из них 30\% дали оценку «отлично»). Для сравнения: в начале эксперимента дали оценку «неудовлетворительно» 80\% респондентов (оценка «отлично» не зафиксирована).

Оценка отдельных компонентов на завершающем этапе эксперимента выявила следующую картину: «высоко» оценили учебно-методическое обеспечение «30\%» и столько же «научно-практическое»; мотивационное обеспечение 25\%, информационно-аналитическое - $20 \%$. Оценка «средне» распределилась так: мотивационное обеспечение - 70\%, учебно-методическое - $60 \%$, информационно-аналитическое - 70\%, научно-практическое 55\%. По всем четырём позициям зафиксирована оценка «низко», она колеблется от 5\% - мотивационное обеспечение, до 15\% - научно-практическое обеспечение, по 10\% - учебно-методическое и информационно-аналитическое. В целом наблюдается позитивная динамика.

Мы можем констатировать, что в результате реализации проекта в дОУ создана система методического обеспечения деятельности педагогов-экспериментаторов, включающая следующие элементы: организационные (корпоративный семинар, консалтинговая служба, творческие группы, педагогические мастерские, мастерклассы), содержательные (разработаны новые методические знания по всем компонентам: мотивационное, учебно-методическое, информационно-аналитическое, научно-практическое).

Резюмируя изложенный материал, отметим, что экспериментальные преобразования, затронувшие методическое обеспечение деятельности педагогов-экспериментаторов по духовно-нравственному воспитанию детей средствами краеведения, изменили ситуацию в лучшую сторону. Научно-методическое обеспечение деятельности педагогов-экспериментаторов стало адресным и целенаправленным, способствующим движению 
педагога к познанию и творчеству с помощью эффективных форм. Считаем, что предложенная технология методического обеспечения не является универсальной, хотя бы потому, что возможны иные подходы при моделировании системы методического обеспечения деятельности педагогов-экспериментаторов по актуальной педагогической проблеме. Но тем не менее считаем, что предложенная технология может быть использована в иных ситуациях, в иных образовательных системах (например, в системе школьного образования).

\section{ЛИТЕРАТУРА}

1. Бондаревская Е.В. Воспитание как встреча с личностью. (Избранные педагогические труды в двух томах). Т.ІІ. - Ростов н/Д: Изд-во РГПУ, 2006. - 504 с.

2. Загвязинский В.И. Теория обучения: современная интерпретация. - М.: Издательский центр «Академия», 2007. - 192 с.

3. Ковалёва Т.М. Инновационная школа: аксиомы и гипотезы. - М.: Изд-во «Московского психолого-социального института»; Воронеж: Изд-во НПО «МОДЭК», 2003. $-256 c$

4. Новиков А.М., Новиков Д.Э. Образовательный проект (методология образовательной деятельности). - М.: «Эгвес», 2004. - 120 с.

5. Саранов А.М., Перекрестова Т.С. Теория и практика становления и развития авторской школы. - Волгоград: Перемена, 2001. - 133 С.

6. Савинова Л.Ф., Янакова К.Г. Модель методического обеспечения деятельности педагогов-экспериментаторов по духовно-нравственному воспитанию дошкольников средствами краеведения. //Современное педагогическое образование, 2019. - №3. - с. 73-77.

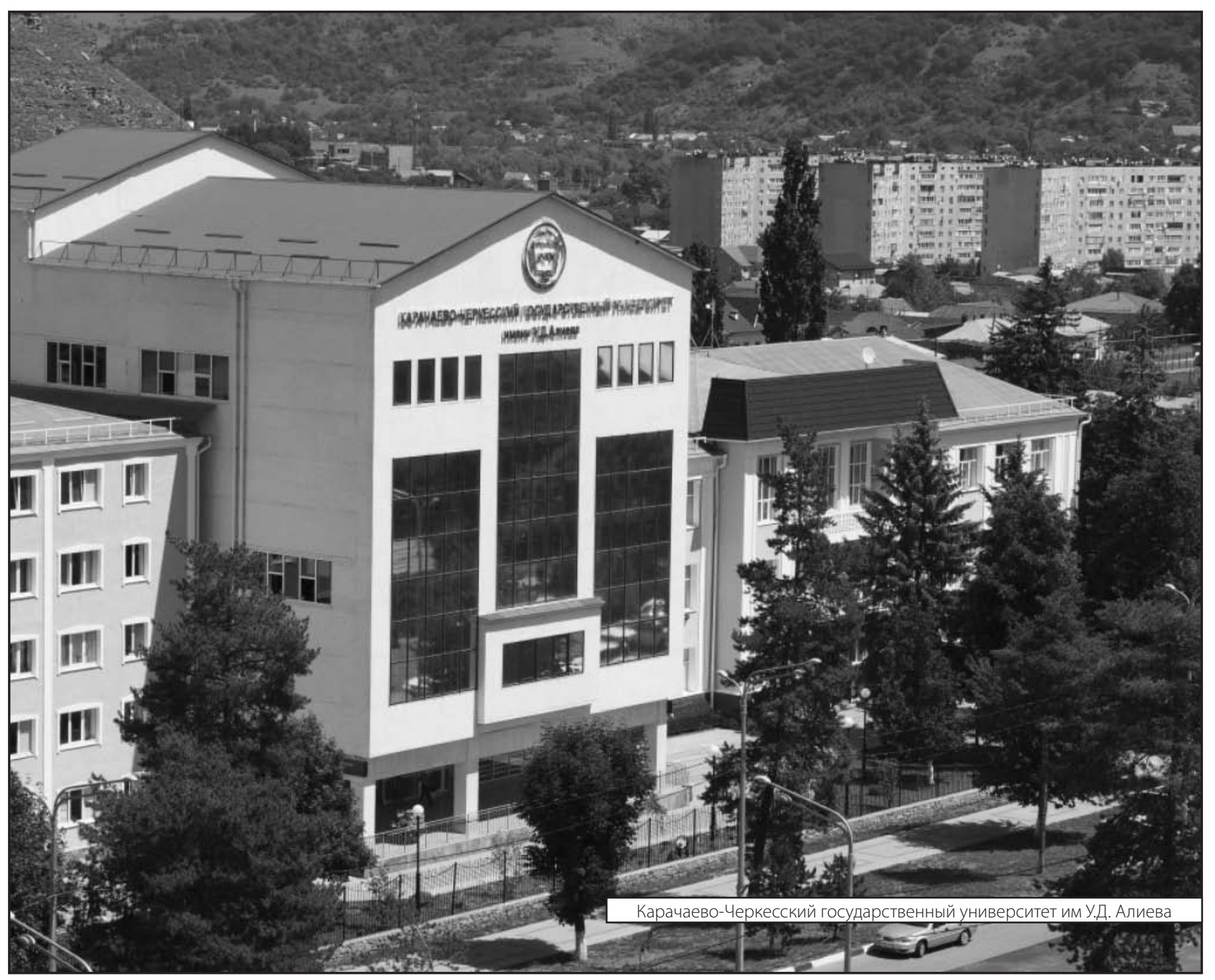

